\title{
Clinical, Economic, and Quality of Life Impact of Atrial Fibrillation
}

\author{
Cynthia A. Sanoski, PharmD, FCCP, BCPS
}

\begin{abstract}
BACKGROUND: Atrial fibrillation (AF) is a common, age-related arrhythmia that disproportionately affects men, adversely affects quality of life, and causes considerable morbidity and mortality.

OBJECTIVES: To describe trends in the prevalence and incidence of $A F$ in the United States; discuss the etiologies and complications of AF; characterize the economic burden of AF; and predict an individual's risk for developing AF and AF-related stroke.

SUMMARY: The prevalence and incidence of AF in the United States are expected to increase in the coming decades because of the aging of the population; improved survival rates associated with coronary heart disease, heart failure, and hypertension; and increased rate of performance of surgical procedures. The economic burden of AF is substantial because of high rates of hospitalization and other health resource utilization. Hypertension, coronary heart disease, and systolic heart failure are the most important risk factors for AF. Ischemic stroke is the most devastating complication of AF. Risk factors for stroke in patients with $\mathrm{AF}$ include recent congestive heart failure, hypertension, advanced age, diabetes mellitus, and a history of stroke or transient ischemic attack. Risk scoring systems have been developed to predict an individual's risk for developing AF and the risk for stroke in a patient with $A F$. The estimated lifetime risk for AF in men and women aged 40 years of age or older is 1 in 4, which is higher than the risk for other diseases that are a common cause for concern among elderly patients.
\end{abstract}

CONCLUSIONS: The clinical and economic burden of AF in the United States is large and will continue to increase in the future. The use of scoring systems to predict the risk of AF and AF-related stroke affords clinicians the opportunity to intervene to minimize these risks and improve patient outcomes.

J Manag Care Pharm. 2009;15(6-b)(Suppl):S4-S9

Copyright $\odot$ 2009, Academy of Managed Care Pharmacy. All rights reserved.

\section{Author}

CYNTHIA A. SANOSKI, PharmD, FCCP, BCPS, is Associate Professor and Chair, Department of Pharmacy Practice, Jefferson School of Pharmacy, Thomas Jefferson University, Philadelphia, Pennsylvania.

AUTHOR CORRESPONDENCE: Cynthia A. Sanoski, PharmD, FCCP, BCPS, Chair, Department of Pharmacy Practice, Jefferson School of Pharmacy, Thomas Jefferson University, 130 9th St., Ste. 1540, Philadelphia, PA 19107-5233. Tel.: 215.503.1722; Fax: 215.503.9052; E-mail: cynthia.sanoski@jefferson.edu

\section{DISCLOSURES}

This learning activity was sponsored by an educational grant from sanofiaventis U.S. Sanoski reports no conflicts of interest related to the subject of this article. She received an honorarium for her participation in the online symposium and for the preparation of this article.

Susan R. Dombrowski, MS, RPh, provided assistance with the medical writing, and Catherine N. Klein, RPh, provided editorial assistance.
A trial fibrillation (AF) is the most common sustained cardiac arrhythmia, affecting approximately 2.2 million Americans. ${ }^{1}$ The prevalence of AF increases with age, with $70 \%$ of cases occurring in patients between the ages of 65 years and 85 years (Figure 1). ${ }^{2}$ Atrial fibrillation is also more common in men than in women at all ages. For example, a cohort of 2,090 men and 2,641 women who participated in the Framingham Heart Study and did not have AF at the time of enrollment were followed for 38 years. ${ }^{3}$ After adjusting for age and other AF risk factors, the men were $50 \%$ more likely to develop AF than were the women. The higher risk of AF in men persisted in each decade between 55 and 94 years of age (Figure 2).

\section{Etiology}

Underlying cardiovascular diseases, including hypertension (HTN), coronary heart disease (CHD), and left ventricular systolic dysfunction are the most common risk factors for AF (Table 1). Other cardiovascular conditions, including left ventricular hypertrophy and valvular heart disease (especially mitral valve disease), are also associated with an increased risk for AF. In general, all of these cardiovascular diseases predispose to AF primarily by causing atrial dilation, which subsequently promotes electrical instability.

Other causes of AF include pulmonary diseases, such as chronic obstructive pulmonary disease and pulmonary embolism, which also can lead to atrial dilation. Atrial fibrillation may also be the result of excessive sympathetic stimulation in patients with hyperthyroidism or alcohol intoxication (i.e., sometimes referred to as "holiday heart" which results from brief binges of alcohol consumption). Surgery, especially cardiothoracic surgery, is a major risk factor for AF because of the excessive sympathetic stimulation that occurs in this setting. Electrolyte abnormalities (e.g., hypokalemia, hypomagnesemia) are also risk factors for arrhythmias in general, including AF. Lone AF occurs in the absence of structural heart disease in patients less than 60 years of age. This form of AF is uncommon, occurring in less than $12 \%$ of all patients with the arrhythmia. ${ }^{4}$

\section{Hemodynamic Consequences}

Atrial fibrillation is often accompanied by a rapid, irregular ventricular rate (i.e., tachycardia), which may manifest as palpitations, hypotension (due to a tachycardia-induced reduction in cardiac output), fatigue, shortness of breath, and reduced exercise tolerance (i.e., a progressive increase in symptoms with increasing amounts of exercise). Patients with underlying ischemic heart disease who develop AF may experience angina because the tachycardia causes an increase in myocardial oxygen demand. Syncope also may occur if the ventricular rate becomes significantly elevated leading to a reduction in cardiac output.

If $\mathrm{AF}$ with a rapid ventricular rate goes untreated for an extended period of time, a tachycardia-induced cardiomyopathy 


\section{FIGURE 1 Relationship Between Prevalence of Atrial Fibrillation and Age}

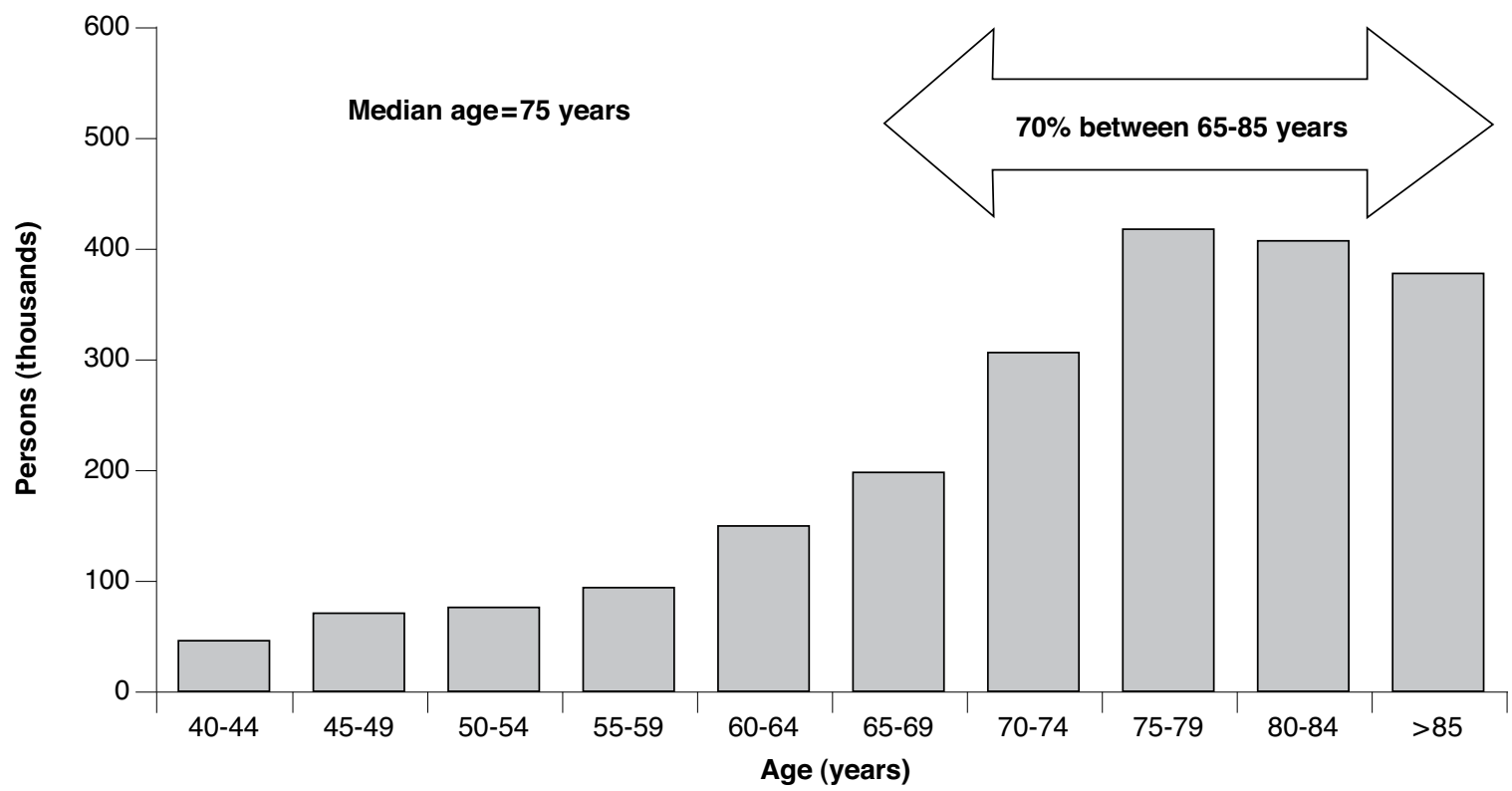

FIGURE 2 Comparative Incidence of Atrial Fibrillation in Men and Women by Age

Framingham Heart Study (38-Year Follow-Up)

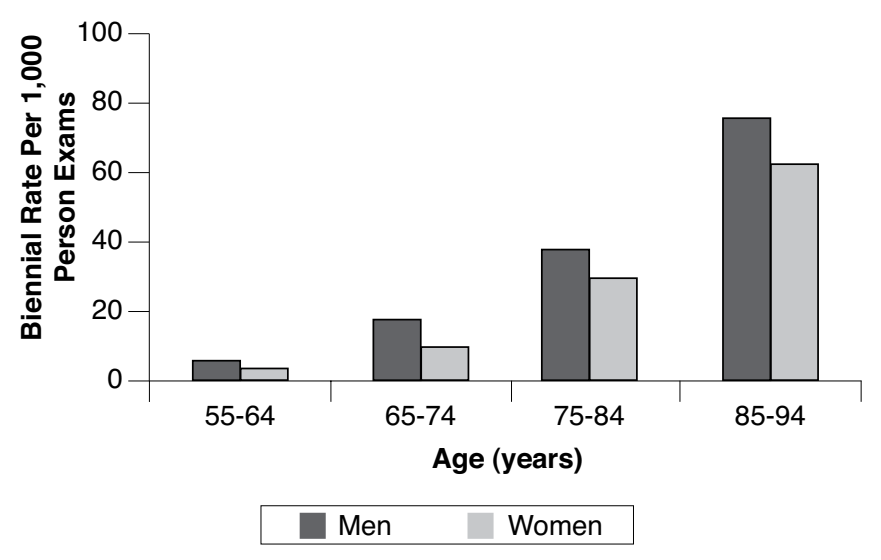

Adapted from Benjamin EJ, et al. ${ }^{3}$

may develop as a result of disturbances in the structure and function of the left ventricle. ${ }^{5}$ The resulting heart failure (HF) may be reversible once the ventricular rate is controlled; however, there is also a possibility that this myocardial damage may be irreversible.

\section{TABLE 1 Risk Factors for Atrial Fibrillation}

Cardiovascular diseases

hypertension, especially with left ventricular hypertrophy

coronary heart disease

systolic heart failure

valvular heart disease

Pulmonary diseases

chronic obstructive pulmonary disease

pulmonary embolism

Hyperthyroidism

Alcohol intoxication ("holiday heart")

Surgery

Electrolyte abnormalities

The development of AF in patients with left ventricular systolic dysfunction often leads to an exacerbation of HF symptoms (e.g., fatigue, shortness of breath, edema) and can result in hospitalization. The AF-induced tachycardia can lead to a reduction in cardiac output, which can induce a worsening of HF symptoms. Additionally, AF can lead to the loss of the patient's atrial "kick," which may also worsen HF symptoms. Ordinarily, patients with systolic HF rely on the contribution of atrial contraction immediately before ventricular systole (i.e., atrial "kick") to increase ventricular filling and cardiac output during ventricular contraction as a compensatory mechanism. This atrial kick often is lost because of the rapid atrial contraction that occurs when 


\begin{tabular}{|c|c|}
\hline Characteristic & Points \\
\hline Recent CHF & 1 \\
\hline Hypertension & 1 \\
\hline Age $\geq 75$ years & 1 \\
\hline Diabetes mellitus & 1 \\
\hline History of stroke or transient ischemic attacks & 2 \\
\hline \multicolumn{2}{|c|}{$\begin{array}{l}\text { Adapted from Gage BF, et al. }{ }^{8} \\
\text { aPatients are considered to be at high risk for stroke if the } \mathrm{CHADS}_{2} \text { score is } 2 \text { or } \\
\text { higher, at intermediate risk if the score is } 1 \text {, and low risk if the score is } 0 .{ }^{8} \\
A F=\text { atrial fibrillation; } C H F=\text { congestive heart failure. }\end{array}$} \\
\hline
\end{tabular}

AF develops in patients with systolic HF, which further compromises cardiac output.

\section{Thromboembolic Consequences}

Thromboembolic complications, namely ischemic stroke, are the most devastating potential consequences of AF. At least 15\%-20\% of all strokes occur in patients with AF.1,6 Atrial fibrillation is an independent risk factor for stroke. ${ }^{6,7}$ In fact, the risk of stroke is increased 4- to 5 -fold by this arrhythmia. ${ }^{6}$ The risk of stroke in patients with AF increases with age, with the annual attributable risk increasing from $1.5 \%$ in patients aged 50-59 years to nearly $24 \%$ in those aged $80-89$ years. ${ }^{7}$ The annual risk of ischemic stroke in patients with AF who do not receive antithrombotic therapy is approximately $5 \% .{ }^{6}$

Various systems for predicting the risk of stroke in patients with AF have been developed. A risk scoring system known as $\mathrm{CHADS}_{2}$ (Table 2) was validated in a study of more than 1,700 Medicare beneficiaries between 65 and 95 years who had nonvalvular AF and were not receiving warfarin at the time of hospital discharge. ${ }^{8}$ In this study, the $\mathrm{CHADS}_{2}$ index was compared with 2 other stroke risk prediction schemes and was found to be the most accurate predictor of stroke in these patients. In fact, the stroke rate per 100 patient-years without antithrombotic therapy increased by a factor of 1.5 for each 1-point increase in the $\mathrm{CHADS}_{2}$ score. $^{8}$

The most recent American College of Chest Physicians (ACCP) guidelines for antithrombotic therapy in $\mathrm{AF}$ have adapted the $\mathrm{CHADS}_{2}$ risk scoring system for stroke risk stratification. ${ }^{6}$ Patients with $\mathrm{AF}$ and a prior ischemic stroke, transient ischemic attack, or systemic embolism (e.g., pulmonary embolism, deep vein thrombosis) or 2 or more of the following risk factors: (a) moderately or severely impaired left ventricular systolic function and/or HF, (b) HTN, (c) age $>75$ years, and (d) diabetes are considered at high risk for stroke. This high risk category corresponds to a $\mathrm{CHADS}_{2}$ score of 2 or more. Patients with AF who have only 1 of the above 4 risk factors (moderately or severely impaired left ventricular systolic function and/or HF, HTN, age $>75$ years, or diabetes) are at intermediate risk for stroke. Patients with $\mathrm{AF}$ who are 75 years of age or younger and have none of the risk factors in the high or intermediate risk categories are at low risk for stroke. The intermediate and low risk categories correspond to a $\mathrm{CHADS}_{2}$ score of 1 and 0 , respectively. This risk stratification process is ultimately used to determine the most appropriate antithrombotic therapy for patients with $\mathrm{AF}$.

\section{Impact on Mortality}

In addition to its impact on morbidity, AF has been associated with an increase in mortality. The mortality trends associated with this arrhythmia were recently evaluated in a community cohort of 4,618 adults who experienced their first documented episode of AF between 1980 and 2000 and were followed until 2004 or their death. ${ }^{9}$ When compared with an age- and gendermatched population that did not have AF, the risk of death was 2 -fold higher in patients with AF $(P<0.001)$. When analyzing these results based upon the time from diagnosis, the mortality risk was even higher within the first 4 months of diagnosis (hazard ratio $[\mathrm{HR}]=9.62,95 \%$ confidence interval $[\mathrm{CI}]=8.93-10.32$ ). However, the increased risk of mortality associated with AF still remained significant beyond the initial 4 months of diagnosis ( $\mathrm{HR}=1.66, \mathrm{CI}=1.59-1.73)$.

The increased mortality associated with AF has been attributed to several possible mechanisms. Currently, it is unclear whether AF itself confers a greater risk of mortality or whether the interaction between $\mathrm{AF}$ and other comorbid conditions provides a substrate for increased mortality. However, data from several studies have linked the increased mortality in patients with AF with the presence of underlying structural heart disease. The presence of AF has been shown to have a detrimental effect on survival in patients with left ventricular (LV) systolic dysfunction. ${ }^{10,11}$ While the mechanisms for increased mortality in patients with HF are likely multifactorial, 1 potential theory is that AF-induced hemodynamic instability may lead to pump failure and eventual death. The development of AF-related stroke also increases the risk of mortality. ${ }^{6}$ In addition, the potential, paradoxical proarrhythmic effects of antiarrhythmics being used to restore and maintain sinus rhythm in patients with AF may also contribute to the increased mortality associated with this arrhythmia.

\section{Quality of Life}

Quality of life is an important consideration for patients with AF. The impact of AF on quality of life has not been extensively evaluated in clinical trials, and only a few of the trials that have been conducted used validated instruments to evaluate quality of life. Most of the studies that have evaluated the impact of treatment strategies on quality of life involved patients who underwent radio frequency ablation procedures. In contrast, relatively few studies have evaluated quality of life at baseline and after initiation of pharmacologic treatment for AF.

In 1 particular study, quality of life was assessed using the 36-item Short Form-36 (SF-36), a generic health scale, in 154 
patients with AF and 49 control subjects without AF. ${ }^{12}$ Total functional capacity was measured using an activity scale, and global life satisfaction was measured using a visual analogue scale (ranging from 1 for worst to 10 for best possible life). Those with AF included 116 patients who were symptomatic and 38 patients with silent AF (i.e., asymptomatic or with very mild symptoms). Patients with AF had significantly worse quality of life compared with control subjects $(P<0.003)$. Furthermore, symptomatic patients with AF had significantly lower scores on the SF-36 than patients with silent AF $(P<0.005)$. Total functional capacity and global life satisfaction also were significantly lower in the symptomatic patients than in those with silent $\mathrm{AF}$ $(P<0.005)$. The results of other studies that have been conducted in patients with AF have been relatively consistent with these findings, showing that AF adversely impacts quality of life and overall well-being. ${ }^{13,14}$

\section{Health Resource Utilization and Costs}

In addition to the adverse impact that $\mathrm{AF}$ has on patients, this arrhythmia has imposed a significant burden on the health care system because of significant utilization of health care resources. In particular, hospitalizations due to AF have significantly increased over the years. In a study that involved patients aged at least 35 years whose data were included as part of the National Hospital Discharge Survey, the number of hospitalizations for AF as the primary diagnosis more than doubled between 1985 and 1999. ${ }^{15}$ The number of hospitalizations for AF as any of 7 possible diagnoses nearly tripled during this time frame.

In another study of 4,498 patients with a new diagnosis of AF, 2,503 patients (56\%) were admitted to the hospital for a cardiovascular cause at least once during a mean follow-up period of 5.5 years. ${ }^{16}$ The likelihood of hospitalization was greatest during the first year after diagnosis of $\mathrm{AF}$, with a cumulative incidence of hospitalization of $31 \%$. The cumulative incidence of hospitalization 3 years and 5 years after diagnosis of $\mathrm{AF}$ was 48\% and 59\%, respectively.

As one might expect, the increased utilization of health care resources with AF subsequently leads to increased health care costs. An analysis of 2001 data from 3 federal databases (the Healthcare Cost and Utilization Project database, the National Ambulatory Medical Care Survey database, and the National Hospital Ambulatory Medical Care Survey database) revealed that approximately 350,000 hospitalizations, 5 million office visits, 276,000 emergency room visits, and 234,000 outpatient visits are attributed to AF annually in the United States. ${ }^{17}$ Attaching costs to these encounters, the total cost of treating AF in 2005 dollars was estimated at $\$ 6.65$ billion, including $\$ 2.93$ billion (44\%) for hospitalizations with a principal discharge diagnosis of AF, $\$ 1.95$ billion (29\%) for the incremental inpatient cost of AF as a comorbid diagnosis, $\$ 1.53$ billion (23\%) for the outpatient treatment of $\mathrm{AF}$, and $\$ 235$ million (4\%) for prescription drugs (Figure 3). The mean cost per AF-related hospitalization exceeded $\$ 8,000$, and the mean length of stay was about 3.5 days.

\section{FIGURE 3 Costs of Treating Atrial Fibrillation}

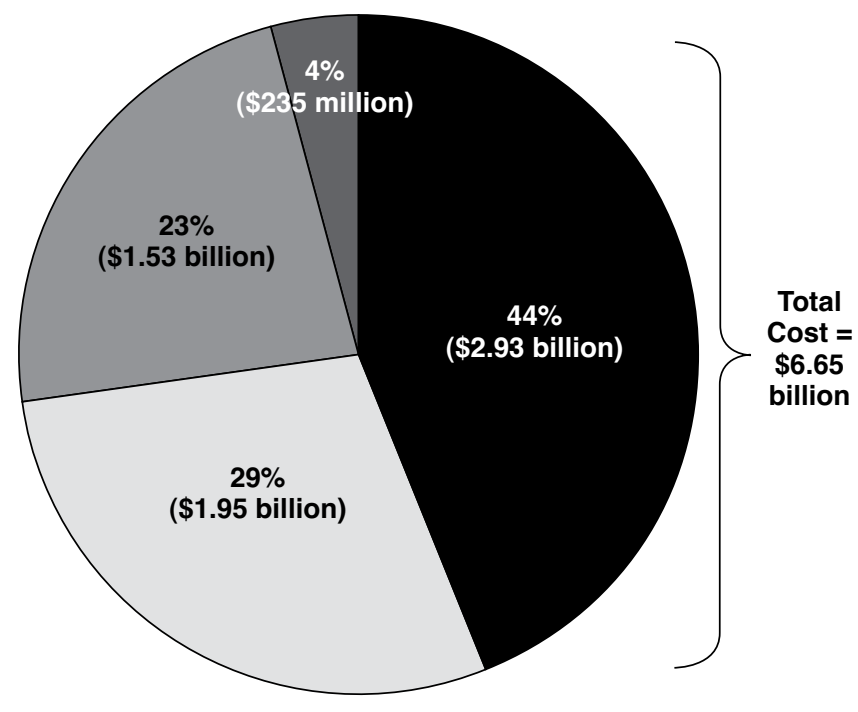

Direct inpatient

Indirect inpatient

Outpatient

Drugs

Adapted from Coyne KS, et al. ${ }^{17}$

\section{Future Burden}

With the aging population, improved survival rates associated with $\mathrm{CHD}, \mathrm{HF}$, and HTN, as well as the increased frequency of surgical procedures being performed, it is expected that the prevalence of $\mathrm{AF}$ will considerably increase in the near future, thereby potentially transforming this disease into a major public health concern. In fact, it is estimated that the prevalence of AF is anticipated to increase by nearly 3-fold to 12.1-15.9 million by the year $2050 .{ }^{18}$

An analysis of more than 8,000 Framingham Heart Study participants who were at least aged 40 years and did not have $\mathrm{AF}$ at the start of the study revealed an estimated lifetime risk of developing AF of $26 \%$ in men and $23 \%$ in women. ${ }^{19}$ The lifetime risk did not change appreciably with advancing age. Therefore, the estimated lifetime risk for AF in men and women at least aged 40 years is estimated to be 1 in 4 . Even when those patients with a prior or current history of HF or myocardial infarction were excluded from the analysis, the lifetime risk of developing AF remained relatively high (1 in 6) despite the absence of these significant risk factors for AF. By comparison, the lifetime risk for HF is 1 in 5 at the age of 40 or older. ${ }^{19}$ The lifetime risk of breast cancer in women is 1 in 8 at the age of 40 and 1 in 14 at the age of 70 . The lifetime risk of hip fracture at the age of 50 


\section{TABLE 3 Risk Scoring System for Determining 10-Year Risk of $\mathrm{AF}^{\mathrm{a}}$}

\begin{tabular}{l|c|c}
\hline Age (yr) & Score (women) & Score (men) \\
\hline $45-49$ & -3 & 1 \\
\hline $50-54$ & -2 & 2 \\
\hline $55-59$ & 0 & 3 \\
\hline $60-64$ & 1 & 4 \\
\hline $65-69$ & 1 & 5 \\
\hline $70-74$ & 4 & 6 \\
\hline $75-79$ & 6 & 7 \\
\hline $80-84$ & 7 & 7 \\
\hline$\geq 85$ & 8 & 8 \\
\hline BMI (kg/m $\left.{ }^{2}\right)$ & \multicolumn{2}{|c}{1} \\
\hline$<30$ & \multicolumn{2}{|c}{0} \\
\hline$\geq 30$ & Score (women and men) \\
\hline Systolic blood pressure (mm Hg) & \multicolumn{2}{|c}{1} \\
\hline$<160$ & \multicolumn{2}{|c}{$\mid$} \\
\hline$\geq 160$ & \multicolumn{2}{|c}{$\mid$} \\
\hline
\end{tabular}

Treatment for hypertension

\begin{tabular}{|c|c|}
\hline No & 0 \\
\hline Yes & 1 \\
\hline PR interval on the ECG (msec) & Score (women and men) \\
\hline$<160$ & 0 \\
\hline $160-99$ & 1 \\
\hline$\geq 200$ & 2 \\
\hline $\begin{array}{l}\text { Age at diagnosis of clinically } \\
\text { significant cardiac murmur (yr) }\end{array}$ & Score (women and men) \\
\hline $45-54$ & 5 \\
\hline $55-64$ & 4 \\
\hline $65-74$ & 2 \\
\hline $75-84$ & 1 \\
\hline$\geq 85$ & 0 \\
\hline Age at diagnosis of heart failure (yr) & Score (women and men) \\
\hline $45-54$ & 10 \\
\hline $55-64$ & 6 \\
\hline $65-74$ & 2 \\
\hline$\geq 75$ & 0 \\
\hline Total score (women and men) & Predicted risk of AF (\%) \\
\hline$\leq 0$ & $\leq 1$ \\
\hline 1 & 2 \\
\hline 2 & 2 \\
\hline 3 & 3 \\
\hline 4 & 4 \\
\hline 5 & 6 \\
\hline 6 & 8 \\
\hline 7 & 12 \\
\hline 8 & 16 \\
\hline 9 & 22 \\
\hline$\geq 10$ & $>30$ \\
\hline
\end{tabular}

Adapted from Schnabel RB, et al. ${ }^{20}$

aThis risk scoring system predicts the 10-year risk of AF in an individual aged 45-95 years based on the total score obtained by adding the scores for each of the seven variables in this table.

$A F=$ atrial fibrillation; $B M I=$ body mass index; $E C G=$ electrocardiogram is 1 in 6 for white women and 1 in 20 for white men. Thus, the overall lifetime risk of $\mathrm{AF}$ is higher than the risk for these other diseases, which further emphasizes the need to develop effective primary prevention strategies to help reduce the prevalence of this arrhythmia in the future.

The substantial morbidity and mortality associated with AF prompted the development of a risk scoring system to predict the risk of developing AF within a 10-year period for individuals aged 45-95 years (Table 3). ${ }^{20}$ This scoring system is based on data from 4,764 participants in the Framingham Heart Study in this age group who did not have AF at the start of the study and were followed for up to 10 years. Seven risk factors associated with AF were identified (age, sex, body-mass index [BMI], systolic blood pressure, treatment for HTN, PR interval, clinically significant heart murmur, and HF), and a point system was developed for use in calculating a total score that corresponds to the 10-year risk for AF in individuals aged 45-95 years. Although this scoring system still requires validation in an independent cohort, it is the first tool available that provides a specific, numerical assessment of an individual's risk for developing AF in 10 years. Therefore, this risk score could then be used as the basis for initiating or intensifying therapies targeted at modifying risk factors for AF (e.g., BMI, systolic blood pressure).

\section{Conclusions}

Atrial fibrillation is a growing public health problem with an economic burden that is expected to increase in the future. The risk for $\mathrm{AF}$ and the risk for stroke in patients with $\mathrm{AF}$ can be predicted, and strategies can be developed to intervene to reduce these risks, thereby minimizing the impact of $\mathrm{AF}$.

\section{REFERENCES}

1. Lloyd-Jones D, Adams R, Carnethon M, et al. Heart disease and stroke statistics-2009 update: a report from the American Heart Association Statistics Committee and Stroke Statistics Subcommittee. Circulation. 2009;119(3):480-86. Available at: http://circ.ahajournals.org/cgi/content/ full/119/2/e21. Accessed July 23, 2009.

2. Feinberg WM, Blackshear JL, Laupacis A, Kronmal R, Hart RG Prevalence, age distribution, and gender of patients with atrial fibrillation. Analysis and implications. Arch Intern Med. 1995;155(5):469-73.

3. Benjamin EJ, Levy D, Vaziri SM, D’Agostino RB, Belanger AJ, Wolf PA. Independent risk factors for atrial fibrillation in a population-based cohort. The Framingham Heart Study. JAMA. 1994;271(11):840-44. Available at: http://jama.ama-assn.org/cgi/reprint/271/11/840. Accessed July 23, 2009 
4. Fuster V, Rydén LE, Cannom DS, et al. ACC/AHA/ESC 2006 Guidelines for the Management of Patients with Atrial Fibrillation: a report of the American College of Cardiology/American Heart Association Task Force on Practice Guidelines and the European Society of Cardiology Committee for Practice Guidelines (Writing Committee to Revise the 2001 Guidelines for the Management of Patients With Atrial Fibrillation): developed in collaboration with the European Heart Rhythm Association and the Heart Rhythm Society. Circulation. 2006;114(7):e257-354. Available at: http://circ.ahajournals.org/cgi/content/full/114/7/e257. Accessed July 23, 2009.

5. Khasnis A, Jongnarangsin K, Abela G et al. Tachycardia-induced cardiomyopathy: a review of the literature. Pacing Clin Electrophysiol. 2005;28:710-21.

6. Singer DE, Albers GW, Dalen JE, et al. Antithrombotic therapy in atrial fibrillation: American College of Chest Physicians Evidence-Based Clinical Practice Guidelines (8th Edition). Chest. 2008;133(6 Suppl):546S-92S. Available at: http://www.chestjournal.org/content/133/6_suppl/546S.full. pdf + html. Accessed July 23, 2009.

7. Wolf PA, Abbott RD, Kannel WB. Atrial fibrillation as an independent risk factor for stroke: the Framingham Study. Stroke. 1991;22(8):983-88. Available at: http://stroke.ahajournals.org/cgi/reprint/22/8/983. Accessed July 23, 2009.

8. Gage BF, Waterman AD, Shannon W, Boechler M, Rich MW, Radford MJ. Validation of clinical classification schemes for predicting stroke: results from the National Registry of Atrial Fibrillation. JAMA. 2001;285(22):286470. Available at: http://jama.ama-assn.org/cgi/reprint/285/22/2864. Accessed July 23, 2009.

9. Miyasaka Y, Barnes ME, Bailey KR, et al. Mortality trends in patients diagnosed with first atrial fibrillation: a 21 -year community-based study. J Am Coll Cardiol. 2007;49(9):986-92. Available at: http://content.onlinejacc.org/ cgi/reprint/49/9/986.pdf. Accessed July 23, 2009.

10. Dries DL, Exner DV, Gersh BJ, Domanski MJ, Waclawiw MA, Stevenson LW. Atrial fibrillation is associated with an increased risk for mortality and heart failure progression in patients with asymptomatic and symptomatic left ventricular systolic dysfunction: a retrospective analysis of the SOLVD trials. Studies of Left Ventricular Dysfunction. J Am Coll Cardiol. 1998;32(3):695-703. Available at: http://content.onlinejacc.org/cgi/content/ full/32/3/695. Accessed July 23, 2009.
11. Wang TJ, Larson MG, Levy D et al. Temporal relations of atrial fibrillation and congestive heart failure and their joint influence on mortality: the Framingham Study. Circulation. 2003;107(23):2920-25. Available at: http:// circ.ahajournals.org/cgi/content/full/107/23/2920. Accessed July 23, 2009.

12. Savelieva I, Paquette M, Dorian P, Lüderitz B, Camm AJ. Quality of life in patients with silent atrial fibrillation (letter). Heart. 2001;85(2):216-17. Available at: http://www.pubmedcentral.nih.gov/picrender.fcgi?artid=172961 7\&blobtype=pdf. Accessed July 23, 2009.

13. Lane DA, Lip GY. Quality of life in older people with atrial fibrillation. J Interv Card Electrophysiol. 2009;25(1):37-42.

14. Thrall G, Lane D, Carroll D, Lip GY. Quality of life in patients with atrial fibrillation: a systematic review. Am J Med. 2006;119(5):448.el-19.

15. Wattigney WA, Mensah GA, Croft JB. Increasing trends in hospitalization for atrial fibrillation in the United States, 1985 through 1999: implications for primary prevention. Circulation. 2003;108(6):711-16. Available at: http://circ.ahajournals.org/cgi/content/full/108/6/711. Accessed May 28, 2009.

16. Miyasaka Y, Barnes ME, Gersh BJ, et al. Changing trends of hospital utilization in patients after their first episode of atrial fibrillation. Am J Cardiol. 2008;102(5):568-72.

17. Coyne KS, Paramore C, Grandy S, Mercader M, Reynolds M, Zimetbaum P. Assessing the direct costs of treating nonvalvular atrial fibrillation in the United States. Value Health. 2006;9(5):348-56.

18. Lloyd-Jones DM, Wang TJ, Leip EP, et al. Lifetime risk for development of atrial fibrillation: the Framingham Heart Study. Circulation. 2004;110(9):1042-46. Available at: http://circ.ahajournals.org/cgi/ reprint/110/9/1042. Accessed July 23, 2009.

19. Miyasaka Y, Barnes ME, Gersh BJ, et al. Secular trends in incidence of atrial fibrillation in Olmsted County, Minnesota, 1980 to 2000, and implications on the projections for future prevalence. Circulation. 2006;114(2):11925. Available at: http://circ.ahajournals.org/cgi/reprint/114/2/119. Accessed July 23, 2009.

20. Schnabel RB, Sullivan LM, Levy D, et al. Development of a risk score for atrial fibrillation (Framingham Heart Study): a community-based cohort study. Lancet. 2009;373(9665):739-45. 